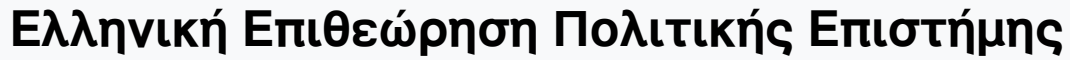

Tó 33 (2009)

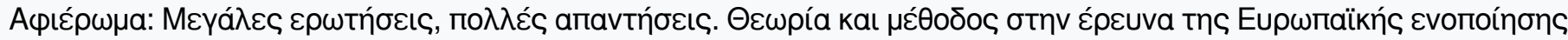

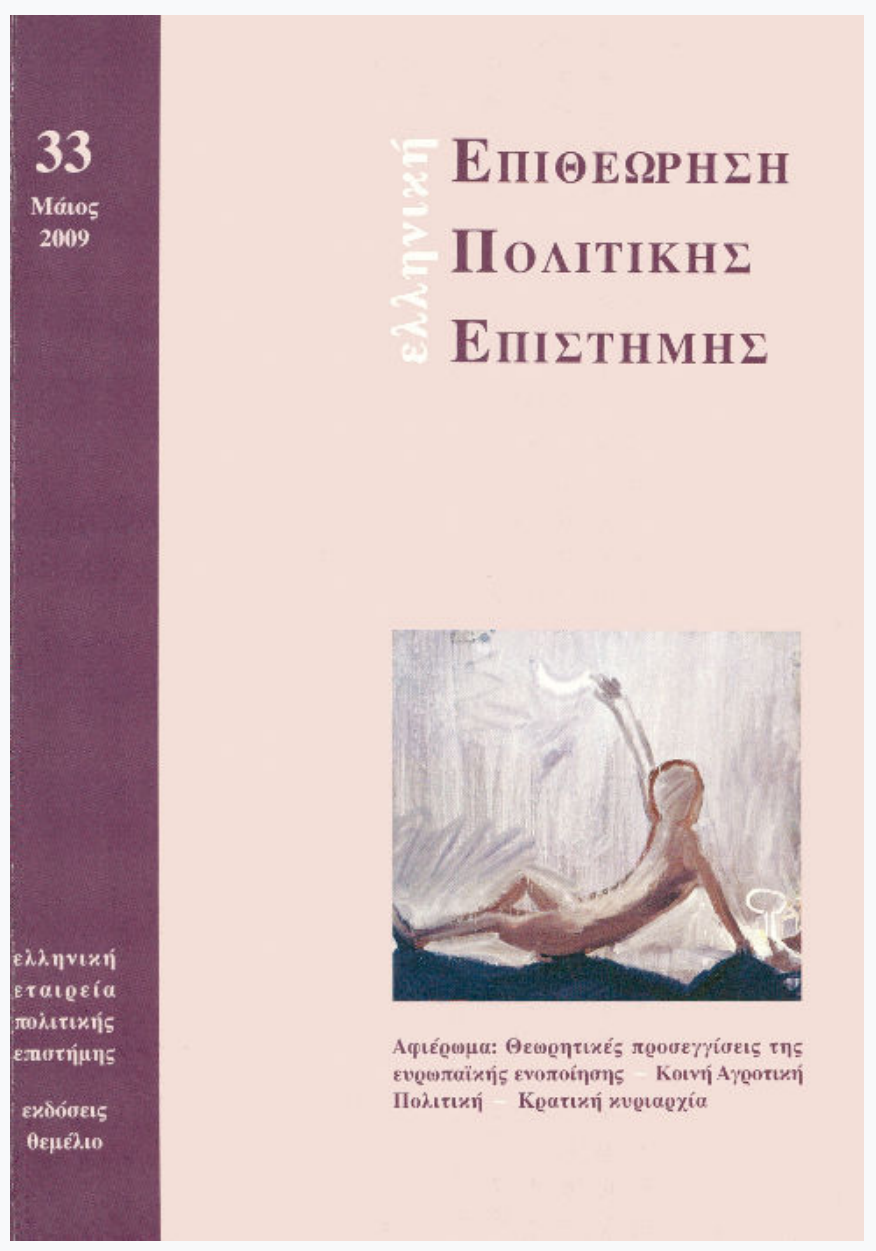

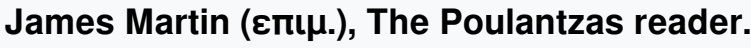

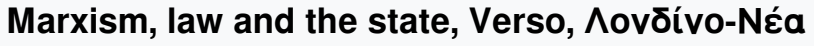

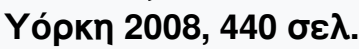

\section{¿пи́рос Макри́s}

doi: $10.12681 / h p s a .14481$

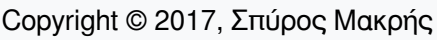

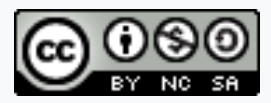

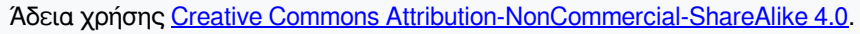

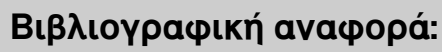

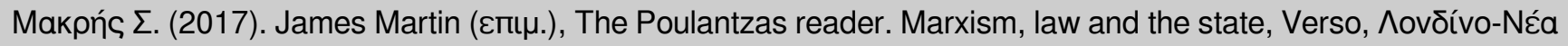

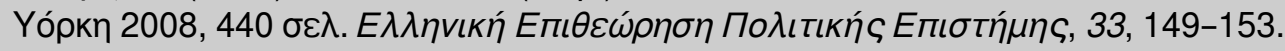

https://doi.org/10.12681/hpsa.14481 


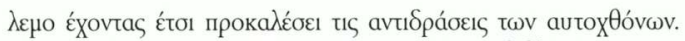

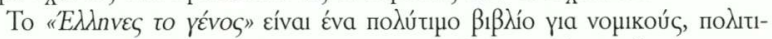

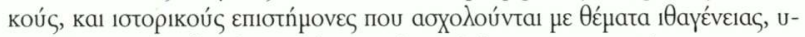

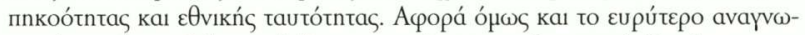

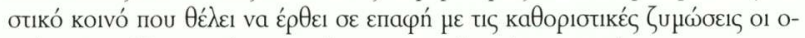

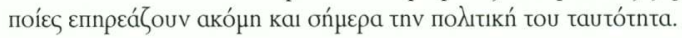

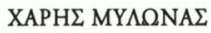

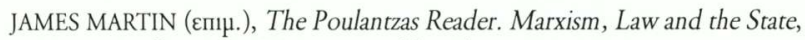

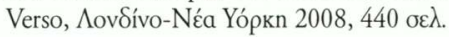

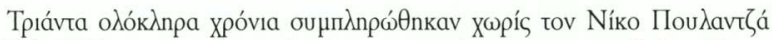

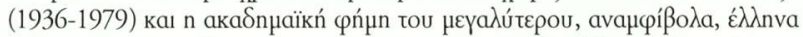

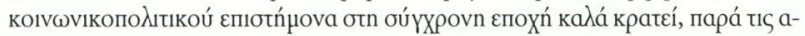

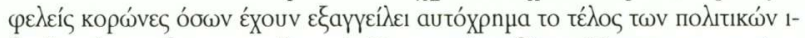

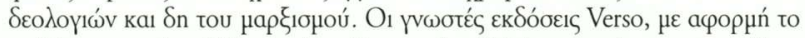

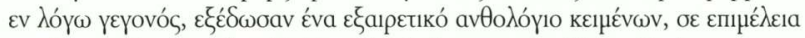

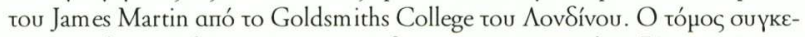

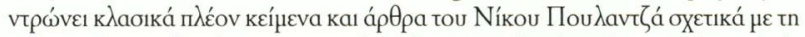

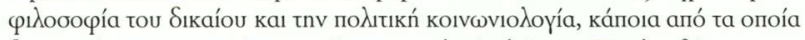

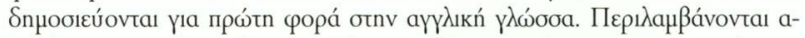

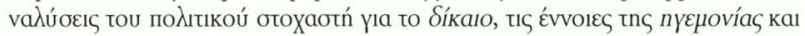

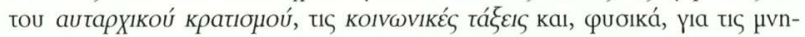

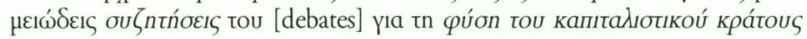

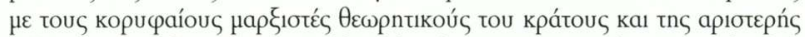

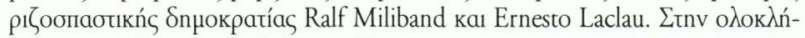

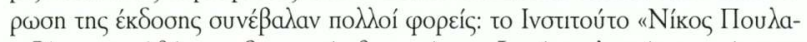

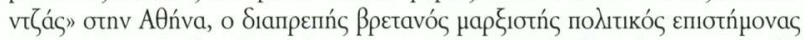

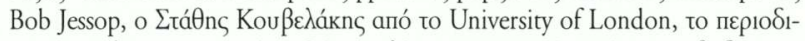

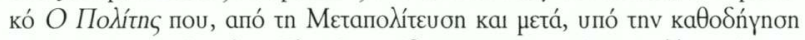

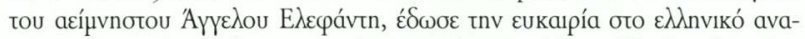

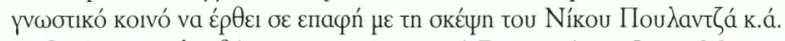

O tó

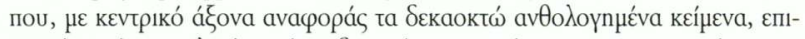

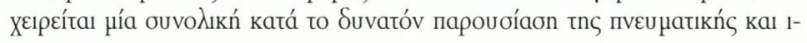




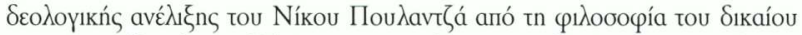

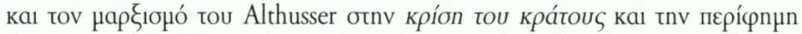

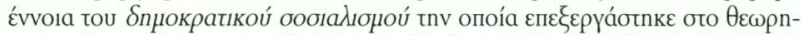

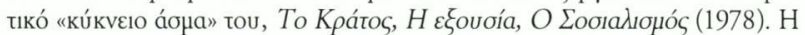

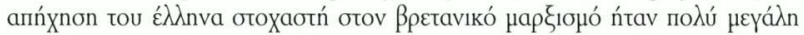

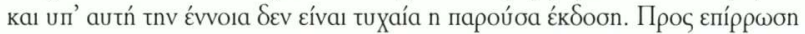

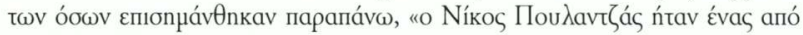

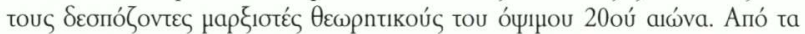

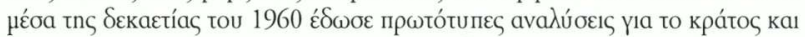

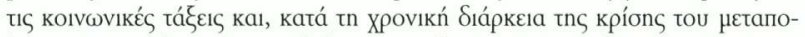

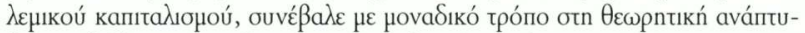

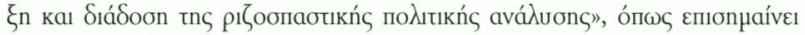

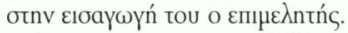

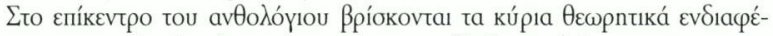

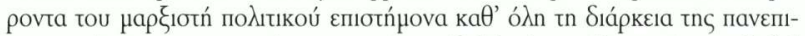

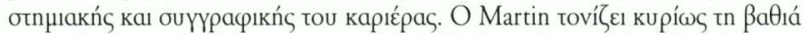

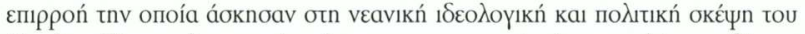

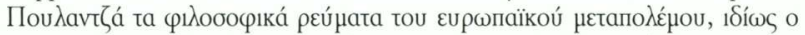

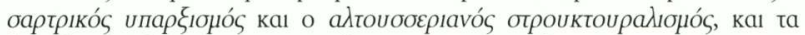

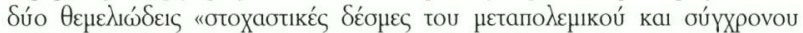

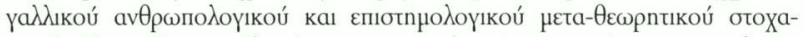

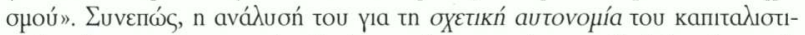

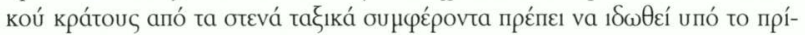

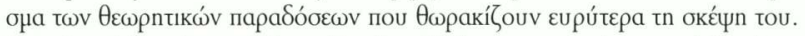

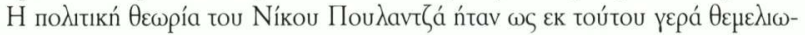

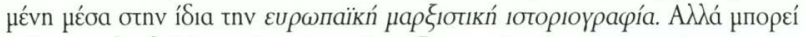

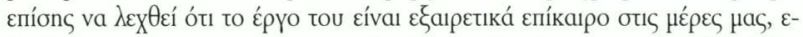

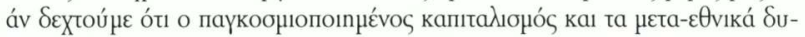

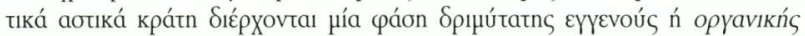

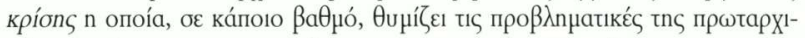

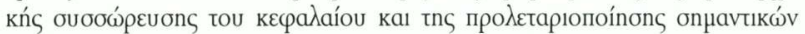

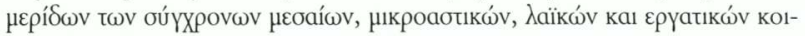

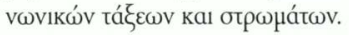

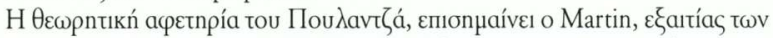

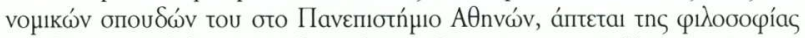

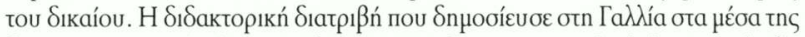

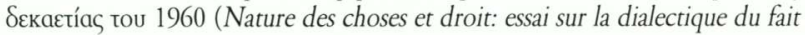




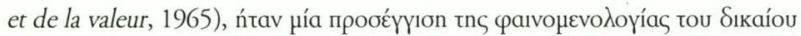

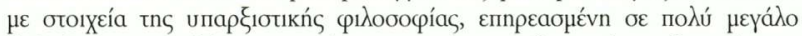

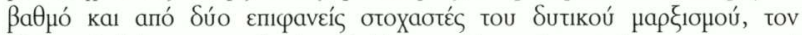

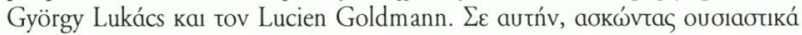

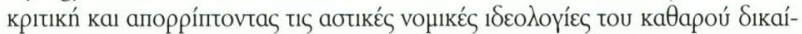

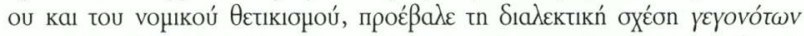

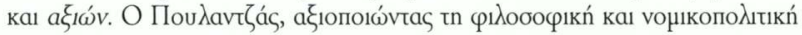

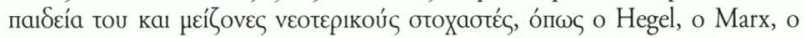

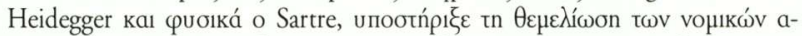

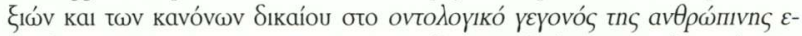

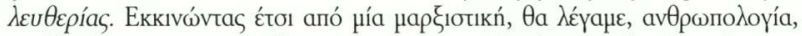

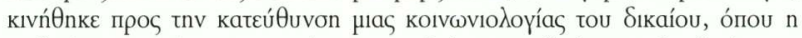

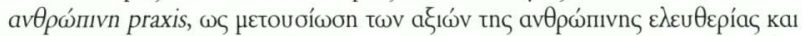

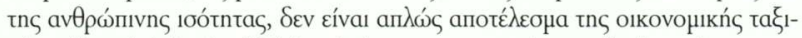

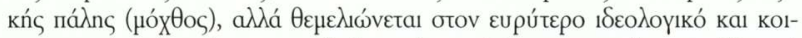

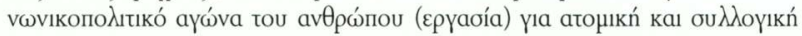

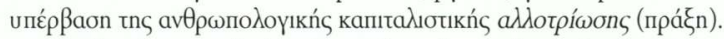

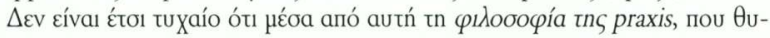

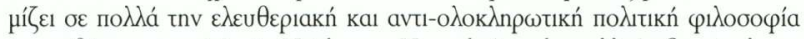

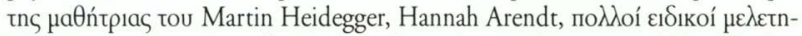

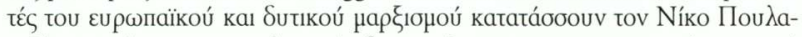

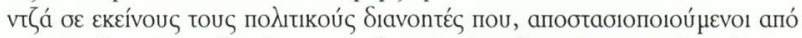

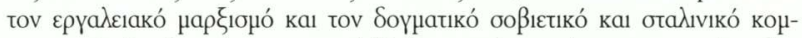

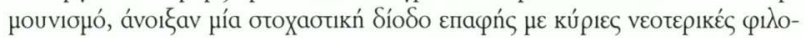

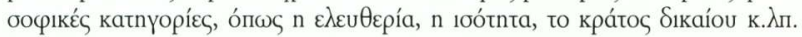

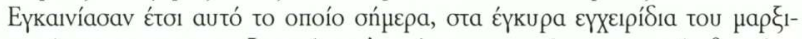

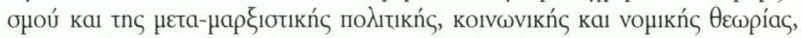

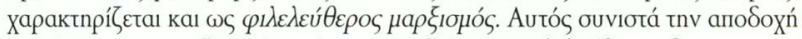

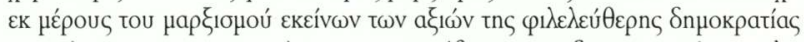

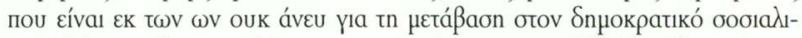

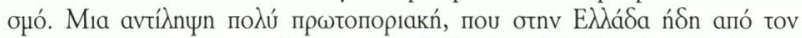

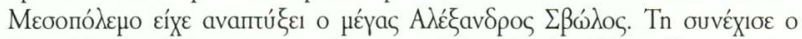

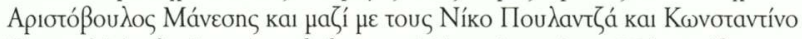

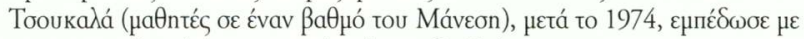

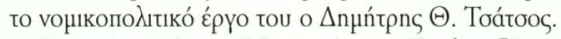

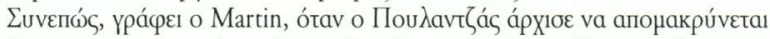

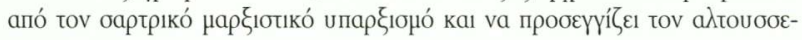




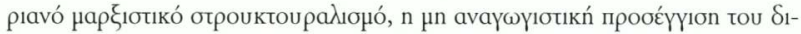

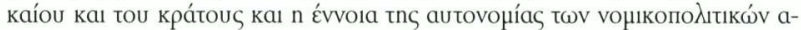

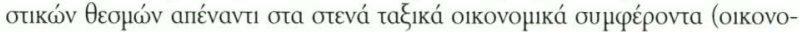

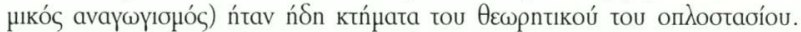

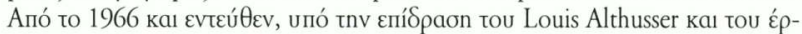

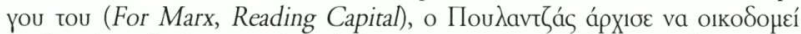

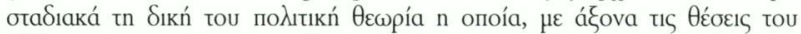

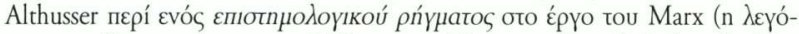

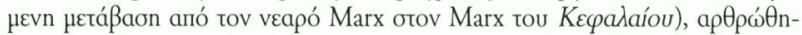

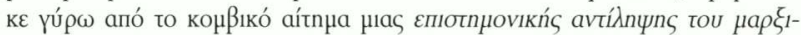

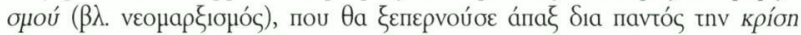

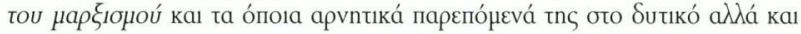

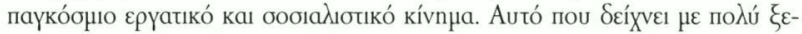

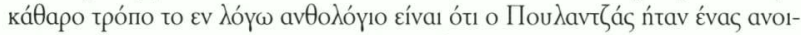

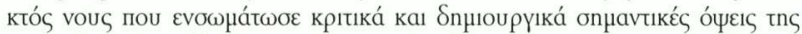

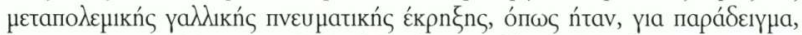

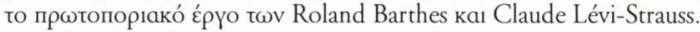

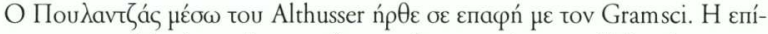

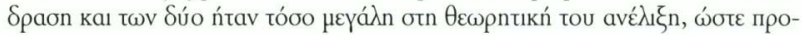

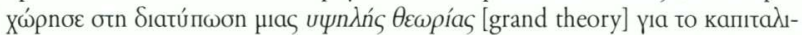

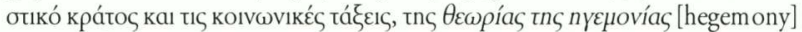

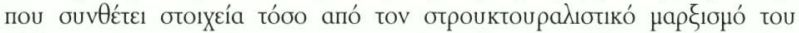

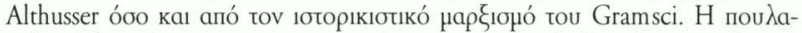

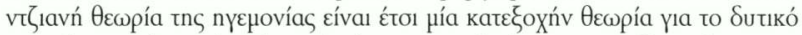

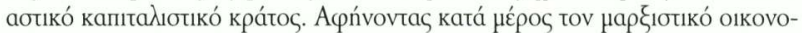

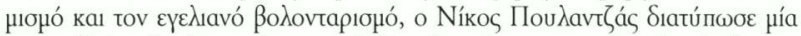

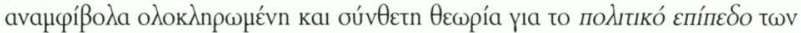

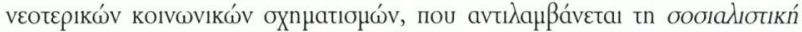

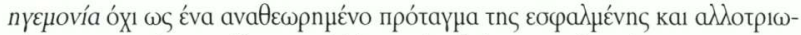

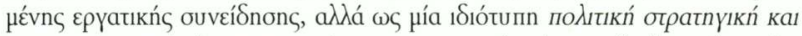

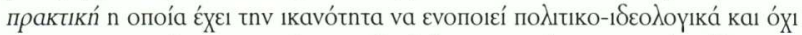

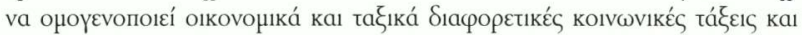

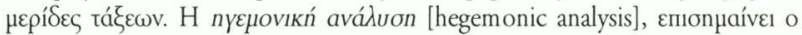

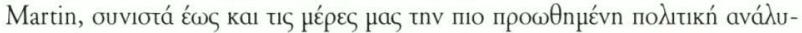

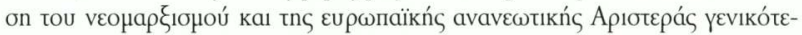

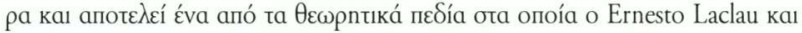

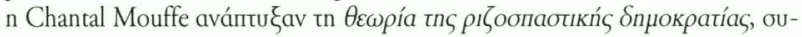




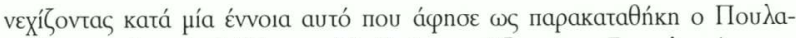

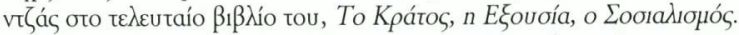

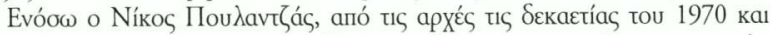

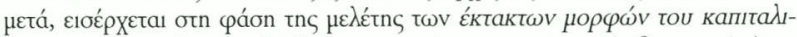

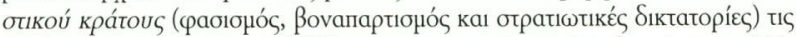

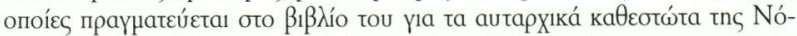

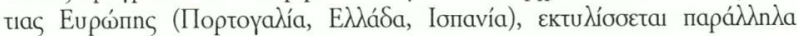

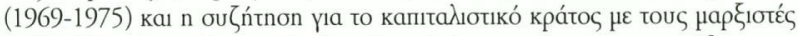

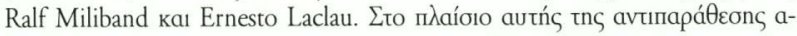

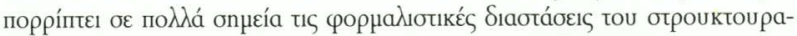

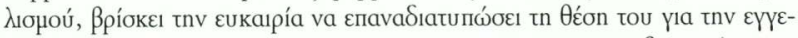

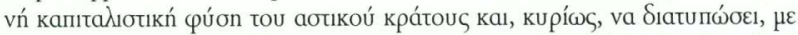

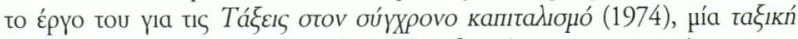

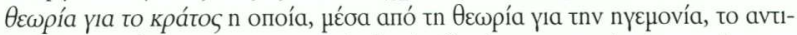

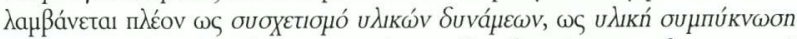

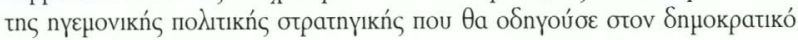
бобıаһıюцó.

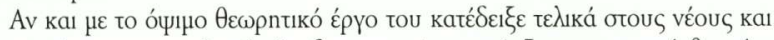

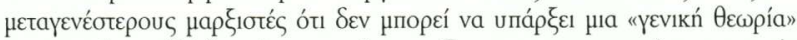

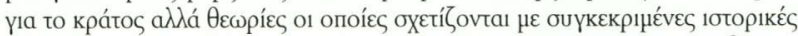

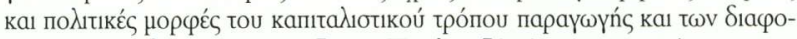

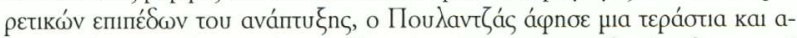

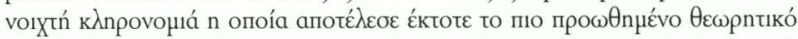

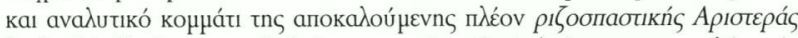

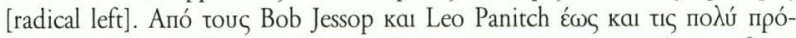

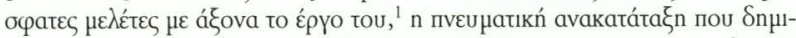

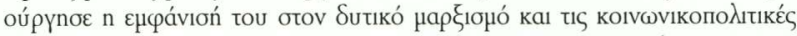

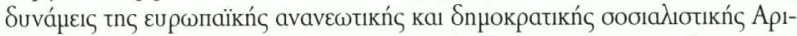

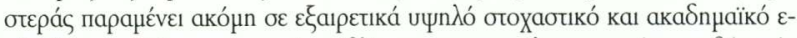

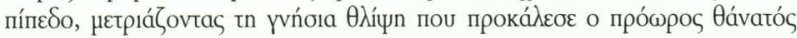

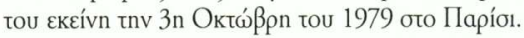

\section{$\Sigma \Pi Y P O \Sigma$ MAKPH $\Sigma$}

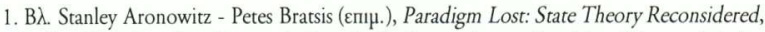

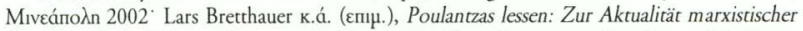
Staatshteorie, A^ßoú pyo 2006, кa Alex Demirovic, Nicos Poulantzas. Aktualität und Probleme

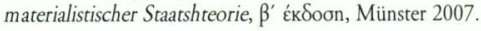

